\title{
On the Co-Occurrence of Warm Conveyor Belt Outflows and PV Streamers*
}

\author{
ERICA MADONNA \\ Institute for Atmospheric and Climate Science, ETH Zürich, Zurich, Switzerland \\ SEBASTIAN LIMBACH \\ Institute for Computer Science, Johannes-Gutenberg University, Mainz, Germany \\ Christine AEBI \\ Oeschger Centre for Climate Change Research, and Institute of Geography, University of Bern, Bern, Switzerland \\ HANNA JOOS AND HEINI WERNLI \\ Institute for Atmospheric and Climate Science, ETH Zürich, Zurich, Switzerland \\ OlIVIA MARTIUS \\ Oeschger Centre for Climate Change Research, and Institute of Geography, University of Bern, Bern, Switzerland
}

(Manuscript received 25 April 2014, in final form 18 July 2014)

\begin{abstract}
The co-occurrence of warm conveyor belts (WCBs), strongly ascending moist airstreams in extratropical cyclones, and stratospheric potential vorticity (PV) streamers, indicators for breaking Rossby waves on the tropopause, is investigated for a 21-yr period in the Northern Hemisphere using Interim European Centre for Medium-Range Weather Forecasts (ECMWF) Re-Analysis (ERA-Interim) data. WCB outflows and PV streamers are respectively identified as two- and three-dimensional objects and tracked during their life cycle. PV streamers are more frequent than WCB outflows and nearly $15 \%$ of all PV streamers co-occur with WCBs during their life cycle, whereas about $60 \%$ of all WCB outflows co-occur with PV streamers. Co-occurrences are most frequent over the North Atlantic and North Pacific in spring and winter. WCB outflows are often located upstream of the PV streamers and form earlier, indicating the importance of diabatic processes for downstream Rossby wave breaking. Less frequently, PV streamers occur first, leading to the formation of new WCBs.
\end{abstract}

\section{Introduction}

Synoptic-scale Rossby waves are disturbances that propagate westward relative to the mean zonal flow along preferred pathways, which are collocated with bands of strong potential vorticity (PV) gradients and strong westerly jets (e.g., Hoskins et al. 1985; Morgan

\footnotetext{
* Supplemental information related to this paper is available at the Journals Online website: http://dx.doi.org/10.1175/JAS-D-140119.s1.

Corresponding author address: Erica Madonna, Institute for Atmospheric and Climate Science, Universitätstrasse 16, ETH Zürich, CH-8092 Zurich, Switzerland.

E-mail: erica.madonna@env.ethz.ch
}

and Nielsen-Gammon 1998). During their life cycle, they can amplify and finally break (Berggren et al. 1949); that is, they undergo a rapid and irreversible deformation where elongated filaments separate from the stratospheric main body, leading to so-called stratospheric PV streamers (Appenzeller and Davies 1992).

Rossby wave breaking (RWB) plays an important role for the upper-level flow as well as for surface weather. It can, for example, assist the formation of atmospheric blocking (e.g., Pelly and Hoskins 2003; Altenhoff et al. 2008; Masato et al. 2012) and reduce the static stability in the midtroposphere and trigger deep tropical convection (Kiladis and Weickmann 1992; Waugh and Funatsu 2003). PV streamers can also act as precursors to heavy precipitation and flooding (Massacand et al. 1998; Martius et al. 2006, 2013), windstorms (Hanley and 
Caballero 2012) over Europe, and U.S. West Coast winter precipitation (Ryoo et al. 2013).

Depending on the initial environmental horizontal shear, Rossby waves can break anticyclonically (LC1) or cyclonically (LC2) (Davies et al. 1991; Thorncroft et al. 1993). The dynamics of Rossby waves can be modified by diabatic effects. Through latent heat release and the associated PV modification, the extratropical wave pattern often amplifies downstream of recurving tropical cyclones undergoing extratropical transition (Atallah and Bosart 2003; Torn 2010; Archambault et al. 2013). A similar mechanism to locally amplify negative PV anomalies in upper-level ridges occurs in warm conveyor belts (WCBs) (Madonna et al. 2014b). WCBs are moist ascending airstreams in extratropical cyclones (Browning 1990), which rapidly ascend from the boundary layer to the upper troposphere in about 1-2 days, leading to cloud formation, (intense) precipitation, and the release of latent heat. Their PV is modified in a significant way and WCBs typically reach the tropopause level with low $\mathrm{PV}$ values $\left[<0.5\right.$ PV units (PVU); 1 PVU $=10^{-6} \mathrm{~K} \mathrm{~kg}^{-1} \mathrm{~m}^{2} \mathrm{~s}^{-1}$ ] (Wernli and Davies 1997; Madonna et al. 2014b). Compared to the climatological PV distribution, these PV values in the WCB outflow constitute significant negative PV anomalies (Madonna et al. 2014b). Therefore, the cross-isentropic transport of low-PV air in WCBs can generate or amplify the upper-level anticyclonic circulation, which in turn can deflect the jet (Davies and Didone 2013), amplify the downstream Rossby wave development (Stoelinga 1996), and contribute to the formation of stratospheric PV streamers downstream (Massacand et al. 2001; Knippertz and Martin 2005; Grams et al. 2011).

Although RWB and therefore the formation of PV streamers are intrinsic to dry dynamics, the case studies cited above indicated the importance of diabatic processes for the wave amplification and eventual breaking. To climatologically quantify the co-occurrence of RWB and diabatically enhanced low-PV anomalies, two existing climatologies of stratospheric PV streamers and WCBs are combined to address the following questions: (i) How often are WCB outflows and PV streamers spatially connected? (ii) Does the WCB outflow typically precede the PV streamer, or vice versa?

The methodology is presented in section 2, the results are presented in section 3 , and the conclusions are presented in section 4 .

\section{Data and methods}

\section{a. PV streamers}

Interim European Centre for Medium-Range Weather Forecasts (ECMWF) Re-Analysis (ERA-Interim) data is used for the Northern Hemisphere from 1989 to 2009 (Dee et al. 2011). Stratospheric PV streamers are identified on isentropic surfaces as two-dimensional filamentary objects using an algorithm developed by Wernli and Sprenger (2007). The considered levels depend on the season: in winter PV streamers are identified from 310 to $330 \mathrm{~K}$ (in increments of $5 \mathrm{~K}$ ), whereas in summer the layer from 330 to $350 \mathrm{~K}$ is considered.

\section{b. Warm conveyor belt outflows}

WCBs are identified with trajectory calculations that select air parcels in the vicinity of cyclones with a minimum ascent of $600 \mathrm{hPa}$ in $48 \mathrm{~h}$, as described in Madonna et al. (2014b). For this study, we consider only WCB outflow regions near the tropopause, since they are characterized by low-PV values and potentially relevant for RWB. Only trajectories that are located above the $310-\mathrm{K}$ isentrope at the end of their ascent (i.e., between time $t=36$ and $72 \mathrm{~h}$ ) are considered. The choice of this $36-\mathrm{h}$ period is based on sensitivity tests (see online supplement) and represents the time window when WCB air parcels have reached the upper troposphere and still form a coherent air mass. At each time step (i.e., every $6 \mathrm{~h}$ ), all the WCB trajectory positions are then gridded on a regular grid with $1^{\circ}$ grid spacing, where each grid point within a radius of $300 \mathrm{~km}$ from the trajectory position received a weighted contribution [see Madonna et al. (2014a, manuscript submitted to Quart. J. Roy. Meteor. Soc.) for details]. This procedure leads to smooth WCB outflow density fields. Connected regions with nonzero density are then defined as twodimensional WCB objects. Small objects with fewer than 20 grid points are neglected.

\section{c. Feature tracking}

To investigate the life cycle of the identified objects (3D PV streamers and 2D WCB outflows) and their spatiotemporal relationship, we use the versatile feature tracking developed by Limbach et al. (2012). For PV streamers, the connectivity of the objects is first investigated in three dimensions across all isentropic levels. Then the features are tracked in time and grouped by considering the spatial overlap of the features at two consecutive time steps. This results in 4D PV streamers and 3D WCBs, each of which represents the development of an individual feature over time. During the tracking, the WCB objects have been enlarged by one grid point in every direction, as discussed in the online supplement. The online supplement presents further details of the algorithm.

From the information about the life cycles of WCB outflows and PV streamers, the co-occurrence of the two can be investigated. We consider WCB outflows and PV 
streamers to co-occur if at least once during their life cycle a spatial overlap of the two features of at least one grid point is found. This definition is restrictive and delineates a lower detection threshold, in the sense that it excludes cases where, for example, a WCB outflow does not reach the PV streamer downstream but could still affect the breaking of the upper-level Rossby wave via its negative PV anomaly.

In addition, for co-occurring features, the following characteristics are determined:

1) Since WCB outflows and PV streamers are tracked from genesis to lysis, it is possible, starting from the first time of co-occurrence, to reconstruct which feature appeared first. For each WCB, it can be detected if it develops before, at the same time, or after the co-occurring PV streamer.

2) The center of mass of PV streamers and WCB outflows is calculated at the time of co-occurrence and their geographical location is compared. A WCB is considered to occur downstream (upstream) of a PV streamer if its center of mass is located to the east (west) of the one of the PV streamers.

\section{Results}

\section{a. Climatology}

From 1989 to 2009, 62124 PV streamers and 8485 WCBs are identified in the Northern Hemisphere. Most PV streamers have a very short life time (more than $50 \%$ exist only at one 6-hourly time step). Only $25 \%$ of the PV streamers live longer than $18 \mathrm{~h}$ and $10 \%$ live for more than 2 days. In contrast, WCB outflows exist longer, with a median lifetime of $36 \mathrm{~h}$ and $25 \%$ living longer than 4 days. In $10 \%$ of the cases, WCB outflows persist for more than 5 days.

The total number of co-occurrences of the two features is 9573 (i.e., on average more than $1 \mathrm{day}^{-1}$ ). The same WCB can interact with different PV streamers and vice versa, but we do not count multiple interactions of the same WCB with the same PV streamer. In total, about $60 \%$ of the WCBs $(\sim 5000)$ co-occur during their life cycle with PV streamers, corroborating the relevant interaction of the two features. In contrast, less than $15 \%$ of the PV streamers $(\sim 8000)$ co-occur with WCBs. It is not surprising that the latter percentage is lower. First, PV streamers can also form without moist diabatic processes. Second, much more PV streamers than WCBs are detected and many of them are short lived. And finally, WCBs are most frequent in winter over the ocean basins (Madonna et al. 2014b) whereas the PV streamer frequency is enhanced in summer over the Asian continent and in the subtropics over the ocean
TABLE 1. Co-occurrences of WCB outflows and PV streamers (\%) by season [December-February (DJF), March-May (MAM), June-August (JJA), and September-November (SON)] for the entire Northern Hemisphere and the North Pacific $\left(120^{\circ} \mathrm{E}-100^{\circ} \mathrm{W}\right)$ and North Atlantic $\left(90^{\circ} \mathrm{W}-0^{\circ}\right)$ basins.

\begin{tabular}{lrrrrr}
\hline \multicolumn{1}{c}{ Co-occurrences } & Total & DJF & MAM & JJA & SON \\
\hline Northern Hemisphere & 100 & 31 & 32 & 14 & 23 \\
North Pacific & 48 & 13 & 16 & 8 & 11 \\
North Atlantic & 28 & 9 & 9 & 3 & 7 \\
\hline
\end{tabular}

basins (Wernli and Sprenger 2007). The PV streamers over Asia form primarily in response to tropical monsoon forcing (Martius et al. 2008) and the PV streamers over the subtropical oceans form downstream of strong subtropical anticyclones (Postel and Hitchman 1999). Thus we expect that, especially in summer, WCBs are not so important for triggering RWB. Hence, most of the co-occurrences are found in spring and winter (more than $30 \%$ ), followed by autumn and summer (see Table 1 ). Co-occurrences happen mainly over the oceans, in the North Pacific $\left(120^{\circ} \mathrm{E}-100^{\circ} \mathrm{W} ; \sim 50 \%\right.$ of the cases) and the North Atlantic $\left(90^{\circ} \mathrm{W}-0^{\circ} ; \sim 30 \%\right)$. The seasonal variation in the two ocean basins reflects the overall seasonal variation, with more interactions in the colder seasons (Table 1).

With respect to the temporal evolution criterion, in about $60 \%$ of the co-occurrences, the WCB outflow exists before the PV streamer. In about $35 \%$ of the cases, PV streamers are detected first and in the remaining roughly $5 \%$, WCB outflows and PV streamers are detected at the same time. Furthermore, we find that it is more likely to find the WCB outflow upstream $(\sim 60 \%)$ than downstream $(\sim 40 \%)$ of the PV streamer (see Table 2; the uncertainty is estimated to be $\pm 3 \%$, as discussed in the online supplement).

\section{b. Illustrative examples}

We briefly present four cases, which show the different types of co-occurrence of WCB outflows and PV streamers as differentiated by their temporal and spatial evolution. The intention is to show typical examples and not to provide a detailed dynamical analysis.

\section{1) WCB UPSTREAM, PREEXISTING}

This case represents the category of WCB outflows preceding the PV streamers and located upstream. Climatologically, this is the most prevalent case with about $35 \%$ of all co-occurring events (Table 2). Figure 1a shows PV at $320 \mathrm{~K}$ over the North Pacific at 0000 UTC 10 December 2008, when we identify a wavelike structure with two troughs. A weak low pressure system is located beneath the eastern flank of the first trough, 
TABLE 2. Percentages of the six categories of co-occurrences of WCB outflows and PV streamers (PVS). Numbers in parentheses refer to the four cases shown in Fig. 1. A reasonable estimate of the uncertainty of these values is $\pm 3 \%$, as discussed in the online supplement.

\begin{tabular}{lccc}
\hline \hline & WCB precedes PVS & PVS precedes WCB & WCB and PVS form at the same time \\
\hline WCB west of PVS & $35(1)$ & $20(3)$ & 4 \\
WCB east of PVS & $23(2)$ & $15(4)$ & 3 \\
\hline
\end{tabular}

approximately at $140^{\circ} \mathrm{E}$. The outflow of the associated WCB (green contour) occurs in the ridge between the two troughs. In the next 12-24 h (Figs. 1b,c), the cyclone intensifies and the WCB outflow becomes larger and spreads toward the pole and the southeast. Thereby the negative $\mathrm{PV}$ anomaly is amplified to the west of the second trough $\left(\sim 180^{\circ}\right)$, inducing an anticyclonic circulation at upper levels, which potentially contributes to the amplification and narrowing of the downstream trough. At 0000 UTC 11 December, the latter forms a PV streamer (black contour in Fig. 1c). This case is qualitatively similar to the one studied by Massacand et al. (2001), who used numerical sensitivity experiments to elucidate the crucial role of the upstream WCB for the downstream RWB.

\section{2) WCB DOWNSTREAM, PREEXISTING}

At 1800 UTC 26 March 2003 (Fig. 1d), a small but intense low pressure system is located near $150^{\circ} \mathrm{E}$ with a WCB outflow downstream. In the next hours (Figs. 1e,f), the WCB outflow expands to the east. It is likely that the latent heating associated with the WCB erodes the stratospheric air at its western flank, which helps the upstream trough to be identified as a PV streamer. This situation is reminiscent of the classical LC2 cyclonic wave breaking (Thorncroft et al. 1993) with cyclonically hooked filaments of high- and low-PV air. Other such examples associated with a WCB outflow were shown by Wernli (1997, his Fig. 13) and Grams et al. (2011, their Fig. 4). In this category, the co-occurrence of the two features is likely a manifestation of a strong diabatically enhanced cyclone intensification. Similar cases are found in more than $20 \%$ of the cases, with a preexisting $\mathrm{WCB}$ downstream of a PV streamer.

\section{3) WCB UPSTREAM, FORMING AFTERWARD}

At 1800 UTC 9 February 1994, two strong cyclones are found in the North Pacific near $150^{\circ} \mathrm{E}$ and $180^{\circ}$, respectively. The downstream cyclone is located beneath a PV streamer (Fig. 1g). The upstream cyclone generates a WCB with an outflow upstream of the preexisting PV streamer (Figs. 1h,i). In this case, the formation of the PV streamer cannot be attributed to the WCB outflow (although, again, low PV values in the outflow induce an anticyclonic circulation). For this category, no causal link exists between the two features. About $20 \%$ of all co-occurrence events fall in this category.

\section{4) WCB DOWNSTREAM, FORMING AFTERWARD}

Figures $1 \mathrm{j}-1$ show a PV streamer identified on the $325-\mathrm{K}$ isentrope over Florida on 21-22 April 1989. A weak surface cyclone is located east of the PV streamer. Then, $12 \mathrm{~h}$ later (Fig. 1k), the surface cyclone is stronger and a WCB outflow is detected downstream of the PV streamer. The situation shown in Fig. 1k is reminiscent of LC1-type wave breaking (Thorncroft et al. 1993) with a fairly weak surface cyclone, a PV streamer upstream, and a WCB outflow that is anticyclonically curved. Again, such a situation was shown by Wernli (1997, his Fig. 12a). The preexisting positive PV anomaly (PV streamer) over a low-level baroclinic region can result in strong cyclonic development, as explained schematically in Hoskins et al. (1985, their Fig. 21). Stronger cyclones potentially enhance the ascent of air masses, assisting the formation of WCBs. About $15 \%$ of the events are in this category with an already formed PV streamer and a subsequent development of WCB downstream.

\section{Conclusions}

We investigated the role of the diabatic modification of upper-level PV associated with WCB for Rossby wave breaking in the extratropics. To this end, we tracked WCBs and PV streamers (i.e., breaking Rossby waves) through their entire life cycle for a $21-y r$ period and investigated their co-occurrence. About $60 \%$ of the WCB outflows overlap during their life cycle with a PV streamer, whereas fewer than $15 \%$ of the PV streamers overlap with WCB outflows. The highest co-occurrence frequency is found during spring and winter over the oceans. The relatively low fraction of PV streamers that are related to WCBs during summer and fall is explained by the fact that, in these seasons, tropical and subtropical anticyclones forced by tropical convection are very important for PV streamer formation.

The analysis of the temporal and spatial cooccurrence of the two features showed that, in about $60 \%$ of the co-occurrence events, the WCB outflow existed before the PV streamer. In $35 \%(23 \%)$ of the cases, the WCB outflow was located upstream (downstream) of the streamer. This corroborates from a climatological perspective the hypothesis that the diabatic $\mathrm{PV}$ modification in WCBs can assist the formation of PV streamers. In the configuration in which the WCB 
a) $2008121000 \mathrm{UTC}, 320 \mathrm{~K}$

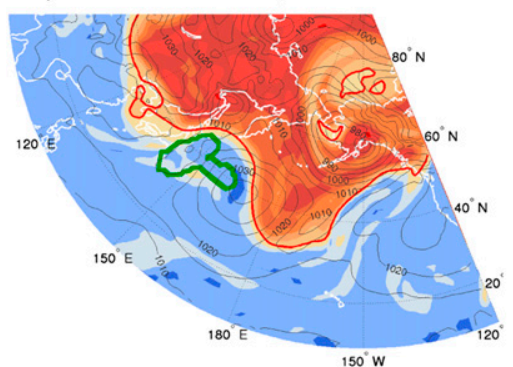

d) $2003032618 \mathrm{UTC}, 320 \mathrm{~K}$

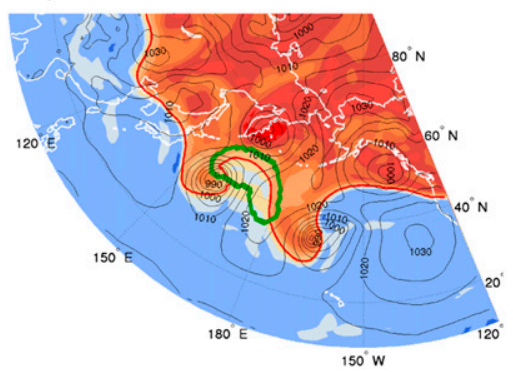

g) $1994020918 \mathrm{UTC}, 320 \mathrm{~K}$

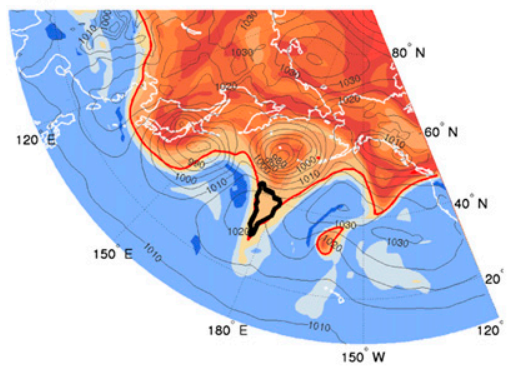

j) $1989042118 \mathrm{UTC}, 325 \mathrm{~K}$

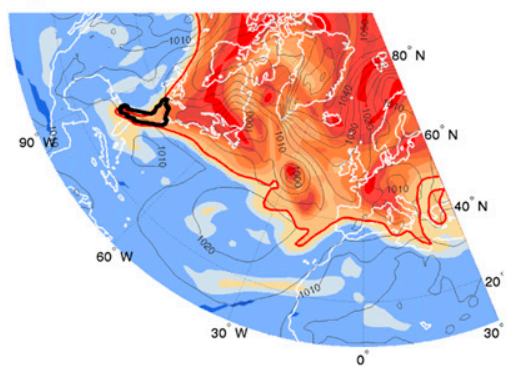

b) $2008121012 \mathrm{UTC}, 320 \mathrm{~K}$

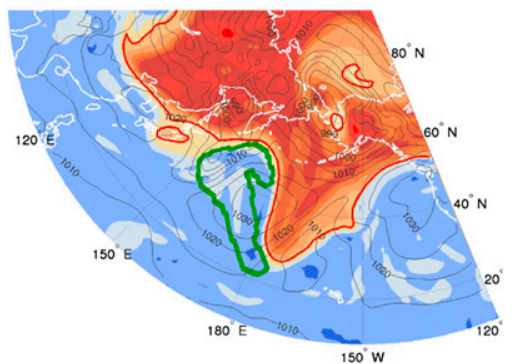

e) $2003032706 \mathrm{UTC}, 320 \mathrm{~K}$

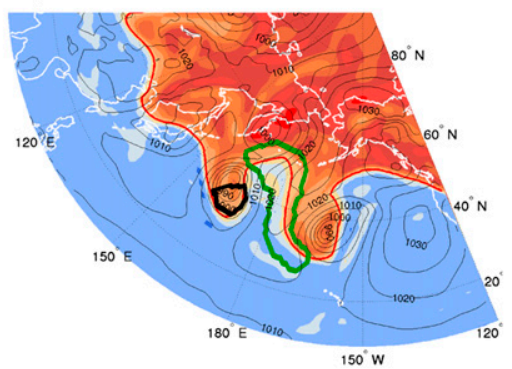

h) 1994021006 UTC, $320 \mathrm{~K}$

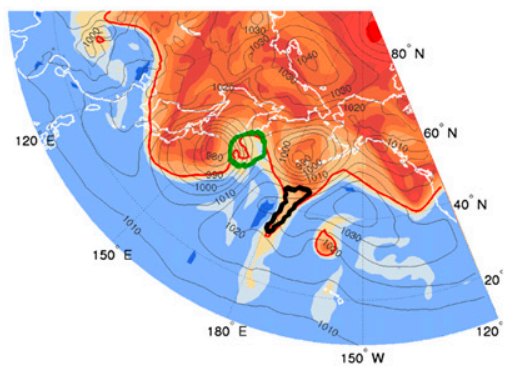

k) 1989042206 UTC, $325 \mathrm{~K}$

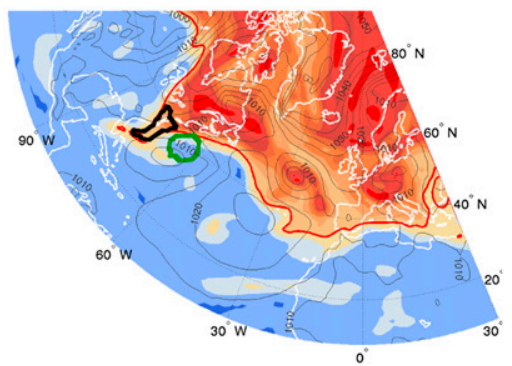

c) $2008121100 \mathrm{UTC}, 320 \mathrm{~K}$

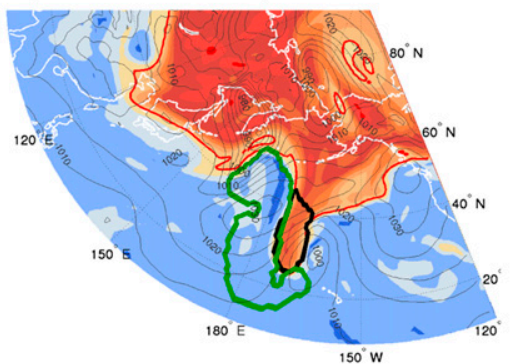

f) $2003032718 \mathrm{UTC}, 320 \mathrm{~K}$

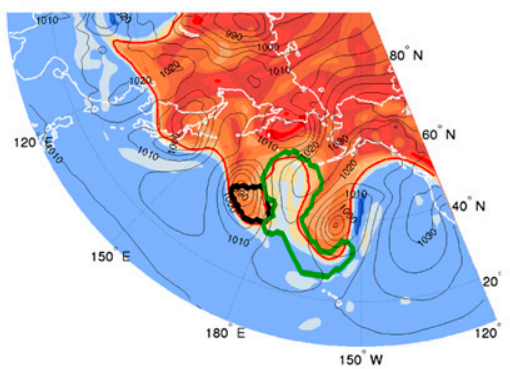

i) $1994021018 \mathrm{UTC}, 320 \mathrm{~K}$

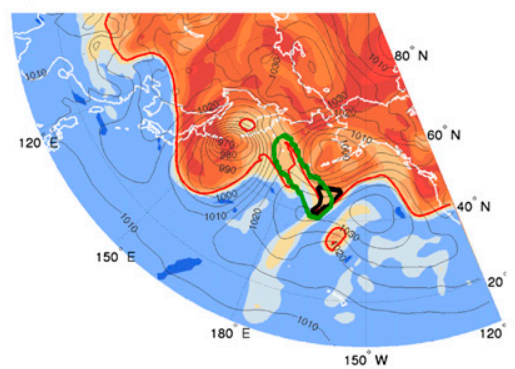

1) $1989042218 \mathrm{UTC}, 325 \mathrm{~K}$

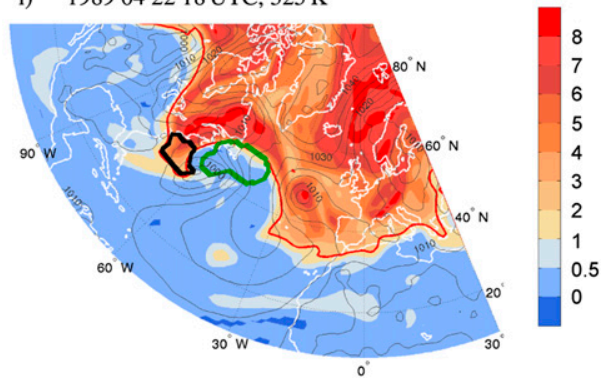

FIG. 1. Four illustrative examples for the co-occurrence of WCBs and PV streamers. Isentropic PV (colors; PVU, 2-PVU line in red) and contours of SLP (every $5 \mathrm{hPa}$ ) for (a)-(c) 10-11 Dec 2008, (d)-(f) 26-27 Mar 2003, (g)-(i) 9-10 Feb 1994, and (j)-(l) 21-22 Apr 1989. The thick green and black contours represent the identified WCB outflows and PV streamers, respectively.

outflow is located upstream of the PV streamer, the WCB outflow can strengthen the ridge, which results in a stronger elongation of the downstream trough into a PV streamer. In the configuration in which the PV streamer is located upstream of the WCB outflow, the latter can erode the upstream trough and thereby contribute to the formation of the PV streamer.

In about $15 \%$ of the cases, PV streamers are located upstream and occur prior to the WCBs. In these cases, the circulation associated with the PV streamer can induce the formation of a surface cyclone and an ascending air mass (WCB) can develop downstream of the cyclone and the PV streamer.

Acknowledgments. EM acknowledges funding by the Swiss National Science Foundation (Project 200021130079). We thank MeteoSwiss and ECMWF for providing access to ERA-Interim and J. M. Chagnon and an anonymous reviewer for their helpful comments, which contributed to the improvement of the article. 


\section{REFERENCES}

Altenhoff, A. M., O. Martius, M. Croci-Maspoli, C. Schwierz, and H. C. Davies, 2008: Linkage of atmospheric blocks and synoptic-scale Rossby waves: A climatological analysis. Tellus, 60, 1053-1063, doi:10.1111/j.1600-0870.2008.00354.x.

Appenzeller, C., and H. C. Davies, 1992: Structure of stratospheric intrusions into the troposphere. Nature, 358, 570-572, doi:10.1038/ 358570a0.

Archambault, H., L. Bosart, D. Keyser, and J. Cordeira, 2013: A climatological analysis of the extratropical flow response to recurving western North Pacific tropical cyclones. Mon. Wea. Rev., 141, 2325-2346, doi:10.1175/MWR-D-12-00257.1.

Atallah, E., and L. Bosart, 2003: The extratropical transition and precipitation distribution of hurricane Floyd (1999). Mon. Wea. Rev., 131, 1063-1081, doi:10.1175/1520-0493(2003)131<1063: TETAPD $>2.0 . \mathrm{CO} ; 2$.

Berggren, R., B. Bolin, and C. G. Rossby, 1949: An aerological study of zonal motion, its perturbations and break-down. Tellus, 1, 14-37, doi:10.1111/j.2153-3490.1949.tb01257.x.

Browning, K. A., 1990: Organization of clouds and precipitation in extratropical cyclones. Extratropical Cyclones: The Erik Palmen Memorial Volume, C. W. Newton and E. O. Holopainen, Eds., Amer. Meteor. Soc., 129-153.

Davies, H. C., and M. Didone, 2013: Diagnosis and dynamics of forecast error growth. Mon. Wea. Rev., 141, 2483-2501, doi:10.1175/MWR-D-12-00242.1.

—_, C. Schär, and H. Wernli, 1991: The palette of fronts and cyclones within a baroclinic wave development. J. Atmos. Sci., 48, 1666-1689, doi:10.1175/1520-0469(1991)048<1666: TPOFAC $>2.0 . \mathrm{CO} ; 2$.

Dee, D. P., and Coauthors, 2011: The ERA-Interim reanalysis: Configuration and performance of the data assimilation system. Quart. J. Roy. Meteor. Soc., 137, 553-597, doi:10.1002/qj.828.

Grams, C. M., and Coauthors, 2011: The key role of diabatic processes in modifying the upper-tropospheric wave guide: A North Atlantic case-study. Quart. J. Roy. Meteor. Soc., 137, 2174-2193, doi:10.1002/qj.891.

Hanley, J., and R. Caballero, 2012: The role of large scale atmospheric flow and Rossby wave breaking in the evolution of extreme windstorms over Europe. Geophys. Res. Lett., 39, L21708, doi:10.1029/2012GL053408.

Hoskins, B. J., M. E. McIntyre, and A. W. Robertson, 1985: On the use and significance of isentropic potential vorticity maps. Quart. J. Roy. Meteor. Soc., 111, 877-946, doi:10.1002/qj.49711147002.

Kiladis, G. N., and K. M. Weickmann, 1992: Extratropical forcing of tropical Pacific convection during northern winter. Mon. Wea. Rev., 120, 1924-1939, doi:10.1175/1520-0493(1992)120<1924: EFOTPC $>2.0 . \mathrm{CO} ; 2$.

Knippertz, P., and J. E. Martin, 2005: Tropical plumes and extreme precipitation in subtropical and tropical West Africa. Quart. J. Roy. Meteor. Soc., 131, 2337-2365, doi:10.1256/ qj.04.148.

Limbach, S., E. Schömer, and H. Wernli, 2012: Detection, tracking and event localization of jet stream features in 4-D atmospheric data. Geosci. Model Dev., 5, 457-470, doi:10.5194/gmd-5-457-2012.

Madonna, E., H. Wernli, H. Joos, and O. Martius, 2014b: Warm conveyor belts in the ERA-Interim dataset (1979-2010). Part I: Climatology and potential vorticity evolution. J. Climate, 27, 3-26, doi:10.1175/JCLI-D-12-00720.1.
Martius, O., E. Zenklusen, C. Schwierz, and H. C. Davies, 2006: Episodes of Alpine heavy precipitation with an overlying elongated stratospheric intrusion: A climatology. Int. J. Climatol., 26, 1149-1164, doi:10.1002/joc.1295.

, C. Schwierz, and M. Sprenger, 2008: Dynamical tropopause variability and potential vorticity streamer in the Northern Hemisphere-A climatological analysis. Adv. Atmos. Sci., 25, 367-379, doi:10.1007/s00376-008-0367-z.

— , and Coauthors, 2013: The role of upper-level dynamics and surface processes for the Pakistan flood of July 2010. Quart. J. Roy. Meteor. Soc., 139, 1780-1797, doi:10.1002/qj.2082.

Masato, G., B. J. Hoskins, and T. J. Woollings, 2012: Wavebreaking characteristics of midlatitude blocking. Quart. J. Roy. Meteor. Soc., 138, 1285-1296, doi:10.1002/qj.990.

Massacand, A. C., H. Wernli, and H. C. Davies, 1998: Heavy precipitation on the Alpine southside: An upper level precursor. Geophys. Res. Lett., 25, 1435-1438, doi:10.1029/98GL50869.

,-- , and — 2001: Influence of upstream diabatic heating upon an alpine event of heavy precipitation. Mon. Wea. Rev., 129, 28222828, doi:10.1175/1520-0493(2001)129<2822:IOUDHU>2.0.CO;2.

Morgan, M. C., and J. W. Nielsen-Gammon, 1998: Using tropopause maps to diagnose midlatitude weather systems. Mon. Wea. Rev., 126, 2555-2579, doi:10.1175/1520-0493(1998)126<2555: UTMTDM $>2.0 . \mathrm{CO} ; 2$.

Pelly, J. L., and B. J. Hoskins, 2003: A new perspective on blocking. J. Atmos. Sci., 60, 743-755, doi:10.1175/1520-0469(2003)060<0743: ANPOB $>2.0 . \mathrm{CO} ; 2$.

Postel, G. A., and M. H. Hitchman, 1999: A climatology of Rossby wave breaking along the subtropical tropopause. J. Atmos. Sci., 56, 359-373, doi:10.1175/1520-0469(1999)056<0359: ACORWB $>2.0 . C O ; 2$.

Ryoo, J.-M., Y. Kaspi, D. W. Waugh, G. N. Kiladis, D. E. Waliser, E. J. Fetzer, and J. Kim, 2013: Impact of Rossby wave breaking on U.S. west coast winter precipitation during ENSO events. J. Climate, 26, 6360-6382, doi:10.1175/JCLI-D-12-00297.1.

Stoelinga, M. T., 1996: A potential vorticity-based study of the role of diabatic heating and friction in a numerically simulated baroclinic cyclone. Mon. Wea. Rev., 124, 849-874, doi:10.1175/ 1520-0493(1996)124<0849:APVBSO > 2.0.CO;2.

Thorncroft, C. D., B. J. Hoskins, and M. E. McIntyre, 1993: Two paradigms of baroclinic-wave life-cycle behaviour. Quart. J. Roy. Meteor. Soc., 119, 17-55, doi:10.1002/qj.49711950903.

Torn, R., 2010: Diagnosis of the downstream ridging associated with extratropical transition using short-term ensemble forecasts. J. Atmos. Sci., 67, 817-833, doi:10.1175/2009JAS3093.1.

Waugh, D. W., and B. M. Funatsu, 2003: Intrusions into the tropical upper troposphere: Three-dimensional structure and accompanying ozone and OLR distributions. J. Atmos. Sci., 60, 637-653, doi:10.1175/1520-0469(2003)060<0637:IITTUT >2.0.CO;2.

Wernli, H., 1997: A Lagrangian-based analysis of extratropical cyclones. II: A detailed case-study. Quart. J. Roy. Meteor. Soc., 123, 1677-1706, doi:10.1002/qj.49712354211.

_ tropical cyclones. I: The method and some applications. Quart. J. Roy. Meteor. Soc., 123, 467-489, doi:10.1002/qj.49712353811.

_ , and M. Sprenger, 2007: Identification and ERA-15 climatology of potential vorticity streamers and cutoffs near the extratropical tropopause. J. Atmos. Sci., 64, 1569-1586, doi:10.1175/JAS3912.1. 